\title{
Personal Resilience of First-Year, Alternatively Certified Agriscience Teachers
}

\author{
D. Barry ${ }^{1}$, A. Warner ${ }^{2}$, S. LaRose ${ }^{3}$, B. Colclasure ${ }^{4}$, E. Osborne $^{5}$
}

\begin{abstract}
A wide range of challenges continues to exist in delivering school-based agricultural education (SBAE) programs. Among the most pressing challenges are the recruitment and retention of high-quality agriculture teachers (Guffey \& Young, 2020). Teacher educators and researchers in SBAE are tasked with meeting the nationwide demand for teachers, while also better understanding the status of alternatively certified agriculture teachers (Foster et al., 2020). This study explored the challenges, coping strategies, and personal resilience of first-year agriscience teachers in Florida who held a temporary teaching certificate. Using a qualitative, phenomenological approach, seven alternatively certified Florida agriculture teachers were interviewed. The personal resilience framework developed by Hoopes (2017) guided this study, as researchers examined alternatively certified teachers' experiences and responses to challenges in their teaching. Emergent themes included prior plans to teach, overwhelming expectations, supportive networks, aspects of resilience, and feelings of motivation and inspiration. This study highlights the need for proactive professional development and support systems for first-year, alternatively certified agriculture teachers.
\end{abstract}

\section{Keywords}

agricultural education, beginning teacher, hardiness, mindset, teacher challenges

1. Debra M. Barry, Assistant Professor, University of Florida, 1200 N. Park Rd., Plant City, Fl. 33563, dmbarry@ufl.edu, (iD) https://orcid.org/0000-0001-9579-3872

2. Anna J. Warner, Assistant Professor, Washington State University, 259 Johnson Hall, PO Box 646420, Pullman, WA 99164-6402, anna.warner@wsu.edu, (iD) https://orcid.org/0000-0003-4683-9912

3. Sarah E. LaRose, Assistant Professor, Purdue University, 915 W. State Street, West Lafayette, IN 47907-2054, slarose@purdue.edu, (D) https://orcid.org/0000-0002-0279-783X

4. Blake C. Colclasure, Assistant Professor, Doane University, 1014 Boswell Ave., Crete, NE 68333, blake.colclasure@doane.edu, (iD) https://orcid.org/0000-0002-8375-286X,

5. Ed W. Osborne, Professor Emeritus, University of Florida, 305 Rolfs Hall, PO Box 110540, Gainesville, FL 32611-0540, ewo@ufl.edu, (iD https://orcid.org/0000-0003-1967-717X 


\section{Introduction and Problem Statement}

The recruitment and retention of agriculture teachers has been a long-standing issue (Guffey \& Young, 2020). Data collected in 2019 from state agricultural education supervisors nationwide indicated more than $25 \%$ of new hires were either alternatively certified or not currently licensed (Foster et al., 2020). Due to the continued growth and expansion in SBAE programs and the inability to fill vacancies with qualified candidates, the demand for teachers has outweighed supply (Foster et al., 2020; Lawver et al., 2018), further contributing to the increase of non-licensed or alternatively certified SBAE teachers (Lawver et al., 2018). Teacher educators and researchers in SBAE need to not only identify the next steps in meeting this demand, but also understand the status of those who are entering the profession.

Some of the greatest challenges and needs of beginning agriscience teachers have included program design and management, teaching, classroom management, and organizing an effective alumni and advisory council (Joerger, 2002; Myers et al., 2005). Emotional burnout is a challenge that many teachers face, with contributors such as an unfulfilled commitment, lack of efficacy, unsupportive administrators, and feelings of overwhelming responsibility (Day \& Gu, 2014; Hong, 2010). Relationships and perceived support in a school community can impact beginning agriculture teachers' job satisfaction and self-efficacy (Hasselquist et al., 2017). When given a supportive workplace environment, many teachers learn to respond positively when faced with challenges, become resilient over time, and can build their resilience in their workplace (Day \& Gu, 2014).

\section{Theoretical and Conceptual Framework}

The personal resilience framework proposed by Hoopes (2017) operationalized the resilience construct for this study. In the book, Prosilience, Hoopes theorized that resilience consists of seven interdependent characteristics. Within the context of responding to challenge and disruptive change, the dimensions of resilience are Positivity (focus on opportunities), Confidence (maintain belief in my capacity to navigate the situation), Priorities (remain focused on the important things), Creative (generate new ideas and approaches), Connection (seek support and assistance from others), Structure (organize my actions), and Experimenting (try new approaches and learn from the experience) (Conner \& Hoopes, 1994)). While one's resilience profile is usually a mix of high, moderate, and low levels of resilience across these seven dimensions, strength in all seven aspects of resilience is optimal (Hoopes, 2017).

Maddi (2013) defined hardiness as the "pattern of attitudes and strategies that constitute the existential courage and motivation to do the hard work of turning stressful circumstances from potential disasters into growth opportunities" (p. 6). The hardy attitudes are remaining engaged in the difficult situation (Commitment), exerting influence where possible (Control), and learning from difficult situations (Challenge). These attitudes are coupled with strategies that include transformational coping, giving and receiving support from others, and healthy self-care (Maddi, 2013). Maddi concluded that a key indicator of hardiness is continuous engagement in 
chores and responsibilities during the developmental years. Contributors to the development of hardiness are a loving and supportive home environment; challenging, yet achievable tasks; and supportive parents who help their children make the most of and learn from challenges and changes in their lives. Hardiness is the essence of resilience (Maddi, 2013).

Day and Gu (2014) provided a comprehensive summary and analysis of research on teacher resilience in their book titled Resilient Teachers, Resilience Schools. Defining teacher resilience as "the capacity to maintain equilibrium and a sense of commitment and agency in the everyday worlds in which teachers teach" (p. 9), these authors suggested that teachers need "everyday resilience" ( $p$. xvii) to successfully manage the multitude of challenges in their teaching. Resilience is not a static trait, but instead fluctuates and is shaped by one's circumstances and environment (Day \& Gu, 2014). In the first of six professional life phases proposed by these researchers, a teacher's developing sense of efficacy is influenced by student behavior, support from school administrators and colleagues, school culture, and recognition of their work. After completing a review of research in the broad literature and in agricultural education, Thieman et al. (2012) concluded that resilience is essential for teacher success.

Dweck's groundbreaking research on mindsets (2017) concluded that people tend to gravitate toward either a fixed or growth mindset (view of themselves), although everyone has dimensions of both. Those with a strong growth mindset accept challenges, try new things, appreciate constructive feedback, enjoy learning and developing, and are comfortable with imperfection. They also recognize that effort, focus, and self-discipline, versus intellect and innate traits, are the keys to their success. On the contrary, others use their fixed mindset as a "suit of armor" (p. 242) to protect their view of themselves, often as perfect or superior, while closing off new ideas and experiences. Dweck concluded that the messages we receive from those around us, beginning at a young age, shape our view of ourselves and our position along the fixed-growth mindset continuum.

\section{Purpose}

The purpose of the study was to explore the challenges, coping strategies, and personal resilience of first-year agriscience teachers in Florida who held a temporary teaching certificate. The overarching research question that guided the study was do alternatively certified first-year agriscience teachers demonstrate resilience as they respond to the challenges they experience in their teaching?

\section{Methods}

Working from a philosophical perspective of constructivism (Crotty, 1998), we used a qualitative approach and phenomenological design (Creswell \& Creswell, 2018) to examine how agriculture teachers respond to the challenges they encounter during their first year of teaching. We examined the resilience of first-year, alternatively certified (AC) agriculture 
teachers, with the expectation that each teacher exhibited aspects of resilience during their first year.

Our execution of the study was informed by our experiences as high school agriculture teachers and university faculty preparing and supporting agriculture teachers. We recognize that our perspectives may pose a potential threat to the trustworthiness of the findings. In order to support trustworthiness of our data, we employed several strategies in our methodology. Two researchers participated in each teacher interview, complete interview recordings and transcripts were prepared, field notes were shared among the researchers, and multiple researchers were involved in the analysis of each interview transcript to strengthen interpretation credibility (Yin, 2016). An attempt was made to share interview transcripts with the participants. However, due to changes in contact information or employment, the researchers were unable to reach two of the teachers. Cell phone or valid email addresses were used to reach the other five teachers. Based on the in-depth interviews conducted and the consistent themes that emerged, the researchers believe the findings are applicable to other first-year, alternatively certified agriculture teachers.

\section{Participants}

The seven participants in the study included all Florida first-year agriculture teachers during the 2017-2018 school year who held a temporary or provisional teaching certificate. Pseudonyms were assigned to each of the seven participants, which included five women, four teachers who were married, five teaching in a program with one agriculture teacher, and one teaching in a new program. Four of the teachers taught in a middle school. All participants held at least a bachelor's degree. None of the teachers had previous school-based teaching experience. Five of the seven teachers in the study completed the Personal Resilience Questionnaire in their first semester of teaching, which generated an individual resilience profile backdrop for the interviews that occurred later in the school year. The average percentile scores were high for two teachers, moderate for two teachers, and low for one teacher. However, the teachers had a mix of high to low scores, with the majority of scores across the seven dimensions of resilience in the moderate or high range.

\section{Data Collection and Analysis}

A semi-structured interview guide was piloted with an agriculture teacher who had completed her first year of teaching. Data from the pilot interview are not included in the findings. All interviews were held immediately after school in the teacher's classroom in May 2018. Interruptions from passersby were brief and inconsequential. Interviews lasted 70-110 minutes, averaging 86 minutes. Only interview data obtained through the 22 questions focused on academic and professional background, challenges in teaching, and personal resilience are reported in this paper.

We worked toward aggregation of the data into a small number of themes, allowing codes or key words to emerge during the data analysis (Creswell \& Creswell, 2018). Two members of the research team independently sifted out the unique ideas and perspectives shared by each teacher in the three areas of focus for this paper. Each researcher then independently 
identified subthemes and major themes from these first-level ideas. We compared our coding outcomes for each interview and found them to have only minor differences in wording. We then developed a final set of subthemes and main themes embedded in each of the interviews. Our final step was to identify the emergent themes across all seven interviews.

Five of the seven participants completed the Personal Resilience Questionnaire (PRQ) (Conner \& Hoopes, 1994) in their first semester, which generated an individual resilience profile. Percentile scores of 35 and below are considered low, and a score in the $65^{\text {th }}$ percentile or higher is considered high (Conner \& Hoopes, 1994). Cronbach's alpha coefficients for five of the seven subconstructs measured by the PRQ (Positivity, Confidence, Priorities, Creative, Connection) range from .71 to .83 , with the other two (Structure, Experimenting) having reliability coefficients of .68 and .65 , respectively (Hoopes, 2013). Prior studies have also demonstrated convergent and discriminant validity of the PRQ (Hoopes, 2013).

\section{Findings}

\section{Not My First Choice}

The first-year agriscience teachers in our study had a wide range of backgrounds. Four of the seven teachers had agriculture coursework and FFA experience in high school and an interest in or experience with animal agriculture. All had earned an agriculture or environmental sciencerelated degree. None of the teachers had formal teacher preparation coursework. Although six of the seven teachers had some interest in teaching while in high school or college, only one of the teachers, Ron, initially planned on pursuing this career path but changed his major midway through college. Allison commented, "the one thing I told everybody, I do not want to go into teaching." Five of the seven interviewed had been employed in a full-time job prior to taking their agriscience teaching position but had felt unsettled and were searching for something more.

\section{Overwhelming Expectations}

None of the first-year teachers interviewed had a clear understanding of the SBAE program structure or school policies and procedures as a teacher. All of the teachers felt overwhelmed by the FFA component of their agriculture teacher responsibilities. Paige explained her view that managing FFA is like "a second job" by saying, "[I] blinked and missed something, all the time. ... When you first come into it, there's no way ... to remember everything or know everything." Many of the teachers shared their frustrations with FFA rosters, registering for events, and the added administrative responsibilities that FFA advisors routinely manage.

Another major challenge shared was the stress of planning and teaching, even while many felt relatively comfortable with most of the technical agriculture content in the lessons. Without a teaching background or education coursework, the teachers felt overwhelmed, unsure, and frustrated. Paige commented, "I initially thought that there was a particular curriculum that was set up and then I was just going to follow. ... That's funny, right?" Allison said, "I knew stuff about ag, and knew I could tell them about ag, but as far as planning to teach them and having 
a well thought out plan on how to keep them engaged, how to keep them interested, those things were what I worried about." Teachers described the overwhelming number of unfamiliar acronyms and the amount of time needed outside of the 40-hour work week. One teacher shared that she expected the hours to be more than a typical job, "but that first two months, three months, it was like 80-90 hours in the week that I was trying to figure out my life." Agriscience teachers routinely shared the difficulties they faced with classroom management and their inability to maintain a consistent, structured learning environment. Mary shared her frustration by acknowledging "there have been two fights in my classroom, both totally unpredictable. So, I mean, it's been hard."

Stress, isolation, and exhaustion were commonly used words to describe the impact of the challenges the teachers faced. Paige recalled one morning, in particular, where students were being disruptive right before an assistant principal stopped by her classroom. "[The principal asked] how are you doing? And I said, I just need a minute, and I started bawling. And I said, I just don't want to talk to you right now. I've never cried in my job, ever."

\section{Supportive Networks}

Teachers, mentors, and administrative staff in the first-year teachers' home school and in other schools formed a highly supportive network for the new teachers. Teachers were often mentioned as the most supportive in helping first-year teachers navigate the challenges of teaching. One teacher described how the local agriscience teachers connected, "We have a text group all the time, or we're asking each other questions. I relied on them heavily this year." Professional Learning Community (PLC) meetings of agriculture teachers in the area proved to be a very useful, albeit intimidating, source of teaching ideas and resources. Paige shared her honest reaction to her first PLC meeting, "When I was listening to those [teachers], I was like, jump ship, jump ship. You're nowhere near this, but every single one of them [said] ... it's like that for like three years." Referring to an agriculture teacher at a nearby school, Ron said, "I've worked with him a lot. They have a very successful program. I didn't know him before I started teaching, but I quickly saw there's good work coming from there." Allison worked closely with a senior agriculture teacher in her county, saying "She's very experienced and so I have lots of phone calls with her, just to even vent."

Other teachers in the school and administrative staff were also very supportive of the first-year teachers in some cases. For example, Mary credited a staff member in her school with helping her become a better teacher. Paige was also grateful for the school counselors taking the time to help her understand school operations, explaining "There's so much to learn about how things run in the school ... I had no idea." Steve mentioned that his first assigned mentor was "awesome," but after she left his new mentor left him "out to dry." In contrast, Natalie said her "buddy" teacher has provided the most support for her, "... helping with getting the hogs to the state fair, with paperwork for this school, understanding schedules. She's definitely been one of the best close-by resources that I've been able to use."

Teachers also expressed their appreciation for programs organized for new teachers. One said, "I found those [sessions] extremely helpful, even for my mental well-being." New teacher 
meetings not only provided the opportunity for an open forum to ask questions and share, but also for peace of mind in knowing that others shared the same struggles.

For some teachers in the study, close friends and family members offered emotional support needed during their first year. Cathy continued to stay in close contact with her former agriculture teacher as a mentor during her first year of teaching. Paige often relied on her close friend for support, saying "I can call him anytime." For those who were married, spouses were invaluable in helping the new teachers talk through their day, de-stress, and stay motivated. Allison described her way of letting go by venting to her spouse, "I go home and vent, then it's over. And then the next day I come in with a fresh new perspective."

\section{Aspects of Resilience}

As a group, the teachers displayed adaptability and resilience during their first year of teaching. They remained positive and hopeful, sought help and ideas from others, and proactively addressed the problems they encountered in teaching. Despite the challenges and stress inherent in their work, they maintained a sense of agency and strong commitment to their teaching. As a supplement to the qualitative data, the resilience profiles obtained for the teachers were mixed but generally reflected moderate to high levels of resilience across the seven dimensions. Steve and Cathy's resilience profiles were in the high range. Ron and Natalie's profiles were in the moderate range, and Allison's overall profile was in the low range. Specific interview questions were posed to uncover precursors to resilience that may have been present in these teachers' lives. In particular, we explored home and school environments, parental expectations, messages from others, exploratory experiences, and chores and responsibilities while growing up (Dweck, 2017; Maddi, 2013).

Six of the seven teachers in the study described themselves as high achievers in school and in other aspects of their life. They enjoyed school and had positive relationships with their teachers and peers. Cathy described her positive connection with teachers by recalling, "My teachers were also very supportive. ... They were always interested in what I did. Even in college, all my professors really liked me, and I could relate to them on a personal level." While in school, all seven teachers were involved in multiple activities beyond their classes and responsibilities at home, with extensive time commitments in several cases. Allison said, "I did everything. ... I was in band, FFA, sports, weightlifting, and track. I did it all."

Parents were supportive and encouraging, while conveying high expectations. Cathy said, "My parents were very supportive in everything that I did ..., so definitely strong, strong family support." Each teacher in the study named a person who was their "champion" - someone who helped shape their self-confidence, determination, and views of opportunity and competition. Natalie said, "I was the pride and joy of my parents. ... They definitely were attached and invested in me throughout my entire youth and still are." Allison said her parents had "expectations to be respectful. ... The kind of person they expected me to be was an upstanding individual towards my teachers and others." 
Messages from these highly influential others focused on working hard to create opportunities for yourself, choosing your own path in life, pursuing your passion, persisting in the face of failure and setback, and discovering your potential. Paige described her mom as her champion - her rock, who always nurtured, encouraged, and supported her, even in her dysfunctional home environment. "Because of that kind of confidence and expectation that she gave me, I've gotten every job that I've applied for, and my jobs have been really cool." Steve described his parents as "encouraging but not overbearing." Natalie said that from elementary to high school she was "always striving to be the top of her class." She attributed her perfectionism to an intentional decision to not repeat the mistakes her biological mother had made in her life. However, her parents always reminded her "that it's not about always being the best, but it's being my best." In contrast, one teacher's parents instilled a competitive drive. Allison recalled this recurring message from her dad, "If you're not first, you're last."

All teachers in the study had daily or weekly chores and responsibilities while growing up. Referring to her family's hay production business, Cathy said, "After school that was my job or on the weekends and over the summer. If I wanted to hang out with my friends, I needed to get my job done first. I fed cows in the morning before I went to school." Steve said, "My nickname was Buddy, because I was my dad's little buddy. I would follow my dad around and help him out with anything I could."

Teachers in the study shared the importance of reflection, learning from mistakes, and understanding that perfection is not the answer. As teachers tackled new obstacles, they felt more confident in their ability to handle issues relating to classroom management, lesson planning, and work balance in their role as an agriscience teacher. The teachers shared numerous accounts of adapting the way they approached their work to improve their general well-being and teaching effectiveness. These included adjustments in time management, work boundaries, stress management, response to setbacks, and teaching strategies. Paige described the need to make herself take a "timeout" from her responsibilities. She took one day during the week to not look at anything work related and described her feeling that "you're never going to be done with it. Making myself have a timeout for a minute has helped." Natalie described how she adapted over the year, "There are literally times I'll be up to like two in the morning, three in the morning, and like ... I shouldn't be doing this. ... So, I've gotten a lot better."

\section{Motivated and Inspired}

Without exception and despite the challenges participants faced during their first year of teaching, all seven teachers expressed unequivocal commitment to doing their best and becoming a better teacher. Cathy said, "Every day I'm actually excited to come to work. I'm excited to see the students' faces or hear their thoughts." One teacher shared a story about a confrontational student and her efforts to connect with the student. After talking with a parent who described his son as "terrible" and developing a plan for working better with the student, the student became one of the hardest working students in her class. 
Although admitting the job was stressful, participants also described teaching as an inspiring and worthy endeavor and were grateful for the opportunity to support student learning and development. Allison commented, "I see my freshmen, how much they've grown in a year, it gets me excited to see where they could be in another three years as seniors and how awesome of a program we could have here." Paige shared how her students inspire her work. "Right now I'm still very much in [teaching]. I've seen changes in students just from being in this class that are monumental. ... That makes it worth it. I'll do all the other stuff."

Even through moments of stress and anxiety, the AC teachers persevered, finding ways to manage the impacts on their lives and general well-being. Natalie shared, "I know that any career and life will have challenges, and these are challenges that I'm willing to accept and work towards getting through and resolving. ... Yeah, I would say I'm still satisfied with teaching." For those with a background in agriculture, teaching agriculture was particularly enjoyable.

The teachers were proud of their accomplishments and were hopeful for the coming year. "My motivation for teaching has definitely increased," said Ron. Natalie offered a very positive view of her year: "I'm in a happy place. ... I feel like I've done a lot. I feel like I'm on a good track." Steve reflected on his first year by saying, "There were times that were really stressful. I feel lucky to get this position. I could have gone anywhere, but I think this is a good start."

\section{Conclusions, Discussion, and Recommendations}

\section{An Array of People and Material Resources is Needed to Support the Success and General Well-Being of First-Year, Alternatively Certified Agriculture Teachers.}

The teachers in this study stepped into their role with no prior professional knowledge or preparation for teaching, leaving them stressed, overworked, and overwhelmed. These findings emphasized the value of established teacher professional support systems that proactively anticipate, monitor, and address the needs of beginning teachers. Thieman, et al. (2012) found that lack of colleague and administrative support is a significant contributor to stress among agriculture teachers. Mentor teachers, school and district administrators, and university faculty should help AC teachers build supportive networks and set reasonable targets for student, program, and teaching improvement in their first year, scaffolding professional development accordingly. School administrators should give special attention to the needs of AC first-year teachers, not assuming they will figure things out over time. Future research should examine the value and impact of these teacher support systems.

\section{Student Progress and a Sense of Accomplishment are Sources of Inspiration and Motivation for First-Year Teachers.}

A surprising finding in this study was that, without exception, teachers were determined to become better teachers, despite feeling behind and unprepared for much of the school year. This unwavering commitment to their teaching was driven by their observations of the academic and personal growth of their students and a sense of accomplishment and progress in their teaching. Research reported by Clemons et al. (2021) also found that student achievement 
is a major factor in agriscience teacher motivation. Future research should take a closer look at the lasting effects of student and teacher accomplishments on teacher motivation and satisfaction.

\section{Alternatively Certified Agriculture Teachers Demonstrate Remarkable Resilience as they Navigate Challenges in their First Year of Teaching.}

Teachers in this study expressed confidence in their ability to become a better teacher, acknowledged their personal and professional growth during their trying first year, and were optimistic about the upcoming school year. Even though the demands of teaching compromised their personal well-being at times, they attempted to adjust their work patterns as they sought better balance. Interview transcripts contained abundant evidence of these teachers as problem solvers - confronting challenges, seeking solutions, and trying new approaches. These dimensions of resilience (Hoopes, 2017) supported teachers' continued commitment and productivity in teaching. The interview data largely mirrored the scores contained in the teachers' resilience profiles. Four of the five profiles were in the moderate to high range. Allison's low resilience, as shown in her profile, appeared to be compensated by her strong, somewhat competitive desire to succeed. Data from her interview showed elements of four resilience dimensions - confidence, priorities, connection, and experimenting. The resilience profiles offered an additional source of data indicating these teachers demonstrated resilience, sometimes at a high level, as they encountered challenges in their teaching. According to Day and Gu (2014), whether teachers find fulfillment in their work and sustain their commitment to teaching “...will depend to a large extent upon the opportunities they have to grow, sustain, and renew their capacities to be resilient" (p. 146). Based on the results of their census study of agriscience teachers in four states, Easterly and Myers (2018) concluded that "resilience should be considered a significant factor in explaining career satisfaction of agriscience teachers" p. 129). A clear understanding of personal resilience and what resilience looks like in the life of an agriculture teacher may be a cornerstone of first-year AC teacher success. Longitudinal studies are needed to further examine teacher resilience in this early career stage.

Life Experiences Develop the Foundation for Teacher Resilience.

Maddi (2013) described hardiness as the essence of resilience, citing chores and responsibilities while growing up as a key predictor of hardiness. All teachers in this study had clear, often extensive, chores during their late childhood and adolescent years. Dweck (2016) concluded that messages from others have a pivotal effect on whether people accept imperfection; believe potential is unknown; work well with others; and are eager to learn, comfortable with uncertainty, unafraid of failure, and open to feedback from others - all characteristics of a growth mindset. Based on their extensive literature review and interviews with a select group of 18 health related professionals, Greene, Galambos, and Lee (2004) concluded that "resilience is an ecological process expressed and affected by multilevel attachments involving families, schools, and communities" (p. 82). Participants in this study shared many examples of the supportive and encouraging messages they received from their teachers and family members, and their positive school experiences carried over into their teaching. They identified one or more "champions" in their life who consistently gave them messages of "find your place" and 
"pursue your dreams," with hard work and without boundaries and limitations. According to Dweck (2016), these types of messages lead to a view of oneself as capable, worthy, learning, and developing. This growth mindset gave these teachers the courage to embark on the journey of an AC agriculture teacher, while knowing that path would be filled with setbacks and unforeseen challenges. Professional support systems and future research should further consider how life experiences shape the foundations of personal resilience in beginning teachers.

\section{References}

Clemons, C. A., Hall, M., \& Lindner, J. (2021). What is the real cost of professional success? A qualitative analysis of work and life balance in agriscience education. Journal of Agricultural Education, 61(1), 95-113. http://doi.org/10.5032/jae.2021.01095

Conner, D., \& Hoopes, L. (1994). Personal Resilience Questionnaire. Resilience Alliance https://resiliencealliance.com/

Creswell, J., \& Creswell, D. (2018). Research design: Qualitative, quantitative, and mixed methods approaches. SAGE.

Crotty, M. (1998). The foundations of social research: Meaning and perspective in the research process. SAGE.

Day, C., \& Gu, Q. (2014). Resilient teachers, resilient schools: Building and sustaining quality in testing times. Routledge.

Dweck, C. (2016). Mindset: The new psychology of success. Random House.

Dweck, C. (2017). Mindset-updated edition: Changing the way you think to fulfil your potential. Robinson.

Easterly III, R. G., \& Myers, B. E. (2018). Personal resilience as a predictor of professional development engagement and career satisfaction of agriscience teachers. Journal of Agricultural Education, 59(1), 119-134. https://doi.org/10.5032/jae.2018.01119

Foster, D. D., Lawver, R. G., \& Smith, A. R., (2020). National agricultural education supply and demand study, 2019 executive summary. American Association for Agricultural Education. https://www.naae.org/teachag/NSD2019\%20Summary 7.15.20.pdf

Greene P. R., Galambos, C. \& Lee, Y. (2004) Resilience theory: Theoretical and professional conceptualizations. Journal of Human Behavior and the Social Environment, 8(3), 75-91. https://doi.org/10.1300/J137v08n04_05 
Guffey, K. B., \& Young, J. S. (2020). Recruitment and retention of agriculture teachers in the Southeast: An empirical analysis of the STAR program. Journal of Agricultural Education, 60(4), 203-313. https://doi.org/10.5032/jae.2020.04203

Hasselquist, L., Herndon, K., \& Kitchel, T. (2017). School culture's influence on beginning agriculture teachers' job satisfaction and teacher self-efficacy. Journal of Agricultural Education, 58(1), 267-279. https://doi.org/10.5032/jae.2017.01267

Hong, J. (2010). Pre-service and beginning teachers' professional identity and its relation to dropping out of the profession. Teaching and Teacher Education, 26(8), 1530-1543. https://doi.org/10.1016/j.tate.2010.06.003

Hoopes, L. (2013). Personal resilience profile handbook. Resilience Alliance. https://resiliencealliance.com/

Joerger, R. M. (2002). A comparison of the in-service education needs of two cohorts of beginning Minnesota agricultural education teachers. Journal of Agricultural Education, 43(3), 11-24. https://doi.org/10.5032/jae.2002.03011

Lawver, R. G., Foster, D. D, \& Smith, A. R. (2018). Status of the U. S. supply and demand for teachers of agricultural education, 2014-2016. American Association for Agricultural Education. http://aaaeonline.org/Teacher-Supply-and-Demand.

Maddi, S. R. (2013). Hardiness: Turning stressful circumstances into resilient growth. Springer.

Myers, B. E., Dyer, J. E., \& Washburn, S. G. (2005). Problems facing beginning agriculture teachers. Journal of Agricultural Education, 46(3), 47-55. https://doi.org/10.5032/jae.2005.03047

Siperstein, G. N., Wiley, A. L., \& Forness, S. R. (2011). School context and the academic and behavioral progress of students with emotional disturbance. Behavioral Disorders, 36(3), 172-184. https://doi.org/10.1177\%2F019874291003600303

Thieman, E. B., Henry, A. L., \& Kitchel, T. (2012). Resilient agricultural educators: Taking stress to the next level. Journal of Agricultural Education, 53(1), 81-94. https://doi.org/10.5032/jae.2012.01081

Yin, R. K. (2016). Qualitative research from start to finish (2nd ed.). Guilford Press.

(C) 2022 by authors. This article is an open access article distributed under the terms and conditions of the Creative Commons Attribution license (http://creativecommons.org/licenses/by/4.0/). 